\title{
Research on Barrier-free Design of House Environment
}

\author{
Hui Wang ${ }^{1, a, *}$, Houping Deng ${ }^{1, b}$ \\ ${ }^{1}$ Gongqing College, Nanchang University, Nanchang, Jiangxi, China \\ a Junjie1231@163.com, b122578942@qq.com \\ *corresponding author
}

Keywords: Barrier-free Design, House Environment, Home Products.

\begin{abstract}
With the improvement of living standard, people pay more and more attention to the quality of life, especially home safety and comfort for families with elderly, disabled and minors, the requirements for all aspects of household design are very high. It leads to the design of a barrier-free home environment to better meet their physical, psychological and behavioral needs and home environment more people-oriented.
\end{abstract}

\section{The concept of barrier-free home design}

The fundamental idea of barrier-free design is that it is convenient design no matter who or where they are. The concept of barrier-free home design means that to analyze and collate the collected basic attributes, furniture physical attributes, environmental physical properties and other relevant information of the physically and mentally disabled, and then formulates the design principles according to the needs. In accordance with the conditions of design principles, to carry out the furniture conceptualization design, and ultimately make it into a specific model. At the same time, under the measurement and evaluation of the design principles, combined with user's participation, the furniture model is tested in a specific scene, and it is analyzed whether it meets the initial requirements of the design. From this, we can see that in the whole process of barrier-free furniture design, the pre-analysis and the formulation of principles are very important, it relates to whether the design of the product can really produce indispensable help to users.

\section{The main suitable body of barrier-free home design}

\subsection{Elderly people in need of fine care}

Nowadays, the aging phenomenon is more and more obvious, especially in China, a large country with a large population. According to the data predicted by the National Bureau of Statistics, the number of old people over 60 years will reach 400 million in 2030. At the same time, China is a country that pursues a "home" culture, people have a strong sense of family, and the home-based care for the elderly are the norm of our lives, because of their specific physical and psychological state, more careful home design is needed. Therefore, attention to design concept of household products mainly as following aspects:

\subsubsection{Dull in feeling}

Because of the aging body, the elderly has declined vision, hearing, and little sense of reception.

\subsubsection{Slow reaction}

Older people are less flexible and less responsive to external stimuli, such as slow movement.

\subsubsection{Poor activity capacity}

The elderly is very weak in physical strength, walking a few steps will be tired, or very likely to fall down, unable to carry out long time activities. 


\subsection{Sun-rising group of minors}

As minors do not have the ability to think independently, they do not understand the dangers of their own behavior, so many home designs may be the source of danger. Children are lively and curious, at the same time they are also in a critical period of personality shaping, the feelings of external things are also very important.

\subsection{The disabled persons with active problems}

For different disabe, his behavior is restricted in different directions. At the same time his psychology is particularly sensitive, the home construction must try to establish a positive and optimistic life attitude for him. He may easily develop loneliness, inferiority, sensitivity, strong self-esteem, ful of compassion and a sense of contradiction. While the environment can affect people, disabled people because of limited activities, very long time at home, so more intimate design needed for their comfortableness, and to expand their degree of social engagement and quality life.

\section{Principles of barrier-free home design}

\subsection{The principle of the old or the disable-orinted}

Barrier-free home takes the elderly as the main body into account, so the barrier-free home design should create a convenient, safe, comfortable and healthy living space in their life, and cultivating and developing their talents, reflecting the care for them. That is, we should apply the idea of "taking the elderly and the disabled as the core" to design the home.

\subsection{The principle of barrier-free to security}

In Maslow's hierarchy of needs, the security is the most basic need of human beings. Only when security need is satisfied, can human beings pursue more advanced needs. Security is very important to all of us. We should take into account the special needs of the disabled and the elderly for safety. They feel particularly insecure because of their own difficult mobility, psychological loneliness and feelings of exclusion. And safety should also be fully reflected in the design of each piece of household products. In particular, their very fragile physical function, once hitting is a life-threatening event. Special attention should be paid to the selection of home materials in reduction of sharp design.

\subsection{Principles adapted to living habits of the elderly disable}

The old and disable living habits are distinct, so residential and home design must be in accordance with their habits, so that they feel comfortable. For example, they move slowly, the movement space is relatively small, so a variety of household visits, tables, chairs height design.

\subsection{Principles for a good indoor and outdoor environment}

Housing is a long-term residence for the elderly and disabled, so their breathing and physical feelings are greatly affected by the living room environment. The flow of the air and the abundance of sunshine will have a positive impact on the health of the human body and the openness of the mood. If the indoor air is not fresh, people will be depressed and difficult in breathing and irritable mood. So in the design must adhere to create a good environment to carry out.

\section{Design of related Furniture products in Barrier-free Home}

There is a very broad market for barrier-free homes. According to this design concept, you can derive a lot of ancillary products. It covers all aspects of our lives, such as big as bedroom, bathroom, kitchen space design, small as wardrobe, bed, bathtub, cabinets and other household details. Attention should be paid to the following issues in the design of related household products. 


\subsection{Barrier-freedesign in kitchen space and related supplies}

The kitchen is an important place to reflect the value of the elderly and the disabled, who can find pleasure in cooking. However, due to physical constraints, if the misuse of kitchen utensils will appear very serious consequences. Because of the diable's mobility difficulty, the chaos of kitchen space will lead to more security risks. Even if just a wire, it is possible an accident to inadvertently trip down. Therefore, the design of the kitchen space must be easy to organize, wide space, and can accommodate the normal operation and accommodate wheelchair or crutches activities as well, and now the development trend of barrier-free kitchen is becoming more and more mechanized.

In particular, to consider some self-help functions, especially for the disable in wheelchairs who have to overcome their inability to stand if they want to cook or eat. So the kitchen should be designed with more consideration of this point. There are currently several forms of barrier-free Kitchen: U Kitchen, I Kitchen, Island Kitchen and parallel Kitchen. Because wheelchair operation in such a space kitchen will be a problem, in the design process it is necessary to consider a variety of data including the wheelchair model, how to open and close the door and size; floor tile material, all kinds of kitchen supplies placing; handrails and mechanized lifting equipment should be added to the design of kitchen elements when necessary to play an auxiliary function.

\subsection{Design of barrier-free toilets and related supplies}

Attention should be paid to the principle of independent operation of sanitary bath design for the old people with disabilities. The design of barrier-free bathroom will open the new field of sanitary products, and it is also the broad direction that production and design enterprises should explore. Due to the intersection of many disciplines in barrier-free design, so there is not a special topic to study. However, with the improvement of people's living standards and the progress of science and technology, people are increasingly aware of the needs of the disabled and the elderly for barrier-free design, among which sanitary products play a very important role.

In the design of sanitary products to add the function of more pleasure, less difficulty to operate, to reduce the burden on the elderly and disabled. Thus, it extends to the analysis of specific elements, such as products' functions, forms, the color, factors of operation interface. And the specific design also depends on different kinds of products. In addition, the design of bathroom space should also be noted, such as wheelchair access, flexible activities. The explored direction is the design integration of bathroom space design and its commodity for the best allocation of resources, namely besides standardization, sanitary ware product should also be customized.

\subsection{Barrier-free bedroom related design and supplies}

Barrier-free housing is very demanding for the bedroom environment, because it specially involves the health of the older and disable. First of all, the bedroom should have a good orientation to ensure adequate sunshine and ventilation; the bedroom is not just for rest, but also for some simple daily activities, such as chat, clothing or learning, then the size of the bedroom must be sufficient. Narrow space is easy for people to produce bad psychological mood, is not conducive to emotional communication. The bedroom is also the person's most self and secret space, so it should remain independent to give the elderly and disabled security; the bedroom furniture's height, width, accessibility, electrical equipment buttons, wires, windows are also some of the details of home decoration products.

\section{Current situation of barrier-free housing in China}

Because the understanding of barrier-free design started relatively late in our country, it generally lags behind times requirements. The rules and regulations for barrier-free design have not yet been established completely. However, with the continuous research of Chinese scholars, the awareness of barrier-free design has been gradually attached important. With the establishment of the related barrier-free trial point and the development of various related experiments, the barrier-free design of the household in China is booming, following the pace of the times with a lot of works and studies 
on barrier-free design constantly coming into our view. The promotion of barrier-free design for our home design and the broad audience to create a comfortable home environment.

\section{Conclusion}

The design of barrier-free home environment, first of all, we should pay attention to this direction, through the analysis of the existing design cases of barrier-free home for the elderly and the disabled, draw on the advanced experience of foreign countries. At the same time, the research should be aimed at the transformation and application of home decoration products. The application involves the design of space layout and furniture, and aiming at the existing architectural form, try to find more suitable, more convenient for the elderly and disabled people's living habits and special needs, strive to build a full of security care, comfortable, convenient, security living environment.

\section{References}

[1] Bin Cheng. (2006) Research on Barrier-free Design of Housing. Civil Engineering and Architecture, 2, 42.

[2] Jiafeng Zhuang. (2014) Research on Research on Barrier-free Design of Multifunctional Household Products . Arts in China, 7, 21.

[3] Liang Wang. (2016) The Penetration of Barrier-free Concept in Home Design. Building Technology Development, 3, 33-34.

[4] Yue Pan. (2014) Study on Barrier-free Design of Home Products for the Elderly, Journal of Ezhou University, 3, 16. 